\title{
Comparison of the efficacy of two insecticides for the management of Dactylopius opuntiae on prickly pear cactus in Lebanon and monitoring of the insecticides residues dissipation rates in fruits and cladodes
}

\author{
Rawan Zeitoun $^{1}$ (D) Salem Hayar ${ }^{1,2,4} \cdot$ Liliane Majed $^{3,4} \cdot$ Khaled El-Omari $^{5} \cdot$ Sylvie Dousset $^{6}$
}

Received: 9 August 2019 / Accepted: 12 December 2019 / Published online: 19 December 2019

(c) Springer Nature Switzerland AG 2019

\begin{abstract}
Environmental conditions and availability of new cultivated areas of prickly pear cactus in Lebanon appeared lately to be favourable for the survival and development of $D$. opuntiae which has become highly noxious. To thwart use of random chemicals and broad spectrum pesticides by local farmers, efficacy of sulfoxaflor (Closer ${ }^{\mathrm{TM}} 240 \mathrm{SC}$, rate $0.179 \mathrm{~kg}$ a.i/ha) and diflubenzuron (Dimilin ${ }^{\circledR} 25 \mathrm{~W}$, rate $0.329 \mathrm{~kg}$ a.i/ha) was compared. Individual insecticidal solutions of each applied alone or in mixing with mineral oil (spray oil $7 \mathrm{E}$, rate $1.010 \mathrm{~kg}$ a.i/ha) on potted cladodes in laboratory conditions $\left(T=23 \pm 4{ }^{\circ} \mathrm{C}\right.$, $\mathrm{RH}=58-63 \%$ ) showed a sharp decrease in the number of individuals within colonies $48 \mathrm{~h}$ after treatment especially among first- and second-instar larvae. Similarly, the same insecticidal solutions applied on separate plots in field conditions $\left(T=20-35^{\circ} \mathrm{C}, \mathrm{RH}=55-75 \%\right)$ according to the Good Agricultural Practices showed efficacious control of the pest development. D. opuntiae mortality mean percentage reached $80 \%$ and $72 \%$, respectively, for sulfoxaflor and diflubenzuron $96 \mathrm{~h}$ after treatment. The added mineral oil acted as a synergist and enhanced efficacy of both insecticides. Mortality mean percentages increased to $92 \%$ and $88 \%$, respectively. Insecticides residues content over time in fruits and cladodes were afterwards monitored. Samples were harvested at 3 days interval and residues extracted by the QuEChERS method and quantified by LC-MS. Dissipation rates after 30 days of treatment attained $70.8 \%$ and $80.6 \%$ in fruits and $98.5 \%$ and $74.0 \%$ in cladodes, respectively, for sulfoxaflor and diflubenzuron. Half-life time varied accordingly and was higher for fruits treated with sulfoxaflor (14.20 days) than for those treated with diflubenzuron (11.18 days). On contrary, for cladodes, half-life time of the former (4.18 days) was lower than that of the latter ( 15.47 days). The addition of mineral oil into the spray solution of the insecticides increased their persistency in the crop. Consequently, half-life times increased and dissipation rates decreased. Findings of this study should enlarge the spectrum of chemical means for $D$. opuntiae management and promote resilience of the crop. Analytical method applied for residues analysis should be useful for registration of the insecticides on the crop and MRLs setting.
\end{abstract}

Keywords Prickly pear cactus · Dactylopius opuntiae $\cdot$ Sulfoxaflor $\cdot$ Diflubenzuron $\cdot$ Mortality mean percentage $\cdot$ Insecticides residues

\footnotetext{
$\triangle$ Rawan Zeitoun, rawan.zeitoun@gmail.com | 'Environmental Health Research Lab (EHRL), Department of Chemistry and Biochemistry, Faculty of Sciences, Section V, Lebanese University, Nabatieh, Lebanon. ${ }^{2}$ Department of Environmental Engineering, Faculty of Agricultural Engineering and Veterinary Medicine, Lebanese University, Dekwaneh-Beirut, Lebanon. ${ }^{3}$ Department of Plant Protection, Faculty of Agricultural Engineering and Veterinary Medicine, Lebanese University, Dekwaneh-Beirut, Lebanon. ${ }^{4}$ Doctoral School of Science and Technology, Research Platform for Environmental Sciences (EDST-PRASE), Lebanese University, Rafic Hariri Campus, Hadath-Mount Lebanon, Lebanon. ${ }^{5}$ Quality Control Laboratories of the Chamber of Commerce, Industry and Agriculture of Tripoli and North-Lebanon, Tripoli, Lebanon. ${ }^{6}$ Laboratoire Interdisciplinaire des Environnements Continentaux, Université de Lorraine/CNRS, BP 70239, 54506 Vandoeuvre-lès-Nancy, France.
} 


\begin{tabular}{|c|c|}
\hline \multicolumn{2}{|c|}{ Abbreviations } \\
\hline DFB & Diflubenzuron \\
\hline SFX & Sulfoxaflor \\
\hline MO & Mineral oil \\
\hline QuEChERS & $\begin{array}{l}\text { Quick, easy, cheap, effective, rugged, and } \\
\text { safe }\end{array}$ \\
\hline LC-MS & $\begin{array}{l}\text { Liquid chromatography coupled to mass } \\
\text { spectrometry }\end{array}$ \\
\hline MRLs & Maximum residues levels \\
\hline ADI & Acceptable daily intake \\
\hline ARfD & Acute reference dose \\
\hline
\end{tabular}

\section{Introduction}

Opuntia ficus-indica (L.) Mill. or prickly pear cactus as commonly known is a crop plant of the Cactaceae family [1], grown in Lebanon in coastal and internal areas where it is essentially intended for fruit production and forage for honeybees [2]. In recent years, cultivations in south of the country have been severely infested by Dactylopius opuntiae (Cockerell), a noxious pest belonging to the Dactylopiidae family in the order Hemiptera that lives feeding on the plant's sap [3]. Natural predator Cryptolaemus montrouzieri Mulsant (Coleoptera, Coccinellidae) was found in conjunction with the colonies, yet its population was very sparse to control the invasive spread of the pest [4]. Nowadays, the increasing propagation of $D$. opuntiae enhanced by the changing weather conditions, the lack of small-scale farmers for the scientific knowledge of the biology, and behaviour of the pest, and the absence of control strategies has resulted in an alarming degeneration of the crop. Fruit and forage production was lowered to more than $90 \%$ which has led to significant losses in the additional income source of local farmers. Thus, concerted action looking for an effective means of control options is crucial in order to maintain the crop's socio-economic value.

Management of D. opuntiae development is documented to rely mostly on biological and chemical methods $[3,5]$. Chemical control should be implemented if the infestation is spreading largely and is momentous particularly when $30 \%$ of the plantations have more than ten colonies [5]. However, only a limited number of conventional insecticides are permitted on cactus plants [5]. Bacterial insecticides such as Bacillus thuringiensis, organic insecticides such as pyrethrum, neem, insecticidal soaps, diatomaceous earth, and mineral oil that yields between 93 and $100 \%$ mortality especially among first- and second instars, paraffinic oils, vegetal oil, and neutral detergents are the most used [5]. These have shown to promote efficacious control of the pest with the benefit of preserving simultaneously lady beetles and syrphid flies in treated fields $[3$,
5-7]. Likewise, several plant extracts have shown promising control of $D$. opuntiae in several countries such as Brazil [3], Morocco [7], and Ethiopia [8]. For instance, extracts of Mentha piperita L. (Lamiaceae) and Mentha spicata L. mixed with different emulsifiers induced body dehydration, obstruction of spiracles, and asphyxia on second instars [9]. Essential oils of Ocimum basilicum L. were effective against first instars [5]. Terpenoids such as eugenol and menthol successfully reduced the number of crawlers [5]. Orange oil provoked death of nymphs and adults within $48 \mathrm{~h}$ after treatment [5]. And, D-limonene from citrus juice was mostly efficacious against adult females and second instars but had little adverse impact on natural predators [7] and caused chlorotic damage to cladodes [10]. Nonetheless, for all of these, further researches are required on spraying coverage and impact speed of the droplets in order to optimize pest control on severely infested areas as is the case in Lebanon. Resolving several aspects related to efficacy, logistic and costs are additionally needed.

Concerning synthetic insecticides, results showed that Neonicotinoids (e.g. thiamethoxam, imidacloprid, thiacloprid, acetamiprid) and Pyrethroids (e.g. lambda-cyhalothrin, bifenthrin) used in Brazil [3], Organophosphates (e.g. chlorpyrifos, malathion, parathion methyl, dimethoate) used in Mexico [11, 12], and Carbamates (e.g. carbaryl) and Pyrethroids (cypermethrin) used in South Africa [13] have been also shown to produce satisfactory curative control against $D$. opuntiae. However, these are recommended in mixtures with neutral detergents for first application, which should be followed by weekly reapplications with alternative materials in case the pest remains present [3]. Moreover, organophosphate dimethoate among others with a control efficacy above $90 \%$ has shown to cause similar mortality on the natural enemies. In addition, thiamethoxam [14], bifenthrin [15], parathion methyl [16], dimethoate [17], and carbaryl [18] are not approved by the EC regulations, and dimethoate, carbaryl, and cypermethrin were recently forbidden in Lebanon [19]. Along with that, chemical control of the pest is hampered by the absence of insecticides registered for prickly pear cactus in the country, as was the case in Brazil until 2016 [3]. Besides, it is to be noted that to date, no pesticide has been registered on the crop by the European Commission or by Codex Alimentarius. Thus, no maximum residues levels (MRLs) were fixed for the commodity fruits $[20,21]$.

Therefore, the present research paper aimed to (1) enlarge the spectrum of chemical means for $D$. opuntiae spread management and (2) contribute in the establishment of norms and MRLs on prickly pear cactus. Thus, the efficacy of sulfoxaflor, a systemic insecticide of the Sulfoximines, and diflubenzuron, a contact insecticide of the Benzoylphenylureas, was evaluated and compared, and persistency of the insecticides residues in the crop was 
monitored and dissipation rates over time determined. Results obtained from a field trial conducted according to the Good Agricultural Practices in response to successful experiments performed on infested cladode samples in laboratory conditions showed that both insecticides could be promising candidates for limiting the pest development, especially when applied in mixture with mineral oil. In addition, their residues were successfully degraded to high rates in the succulent cladodes and fruits approximately 1 month after spraying. The assessment of the insecticides residues in the plant material represents the originality of the study and is useful in the determination of minimum intervals between application and harvest to keep residues levels as low as possible and ensure safe application of the insecticides. This should eventually lead to the registration of these phytosanitary products on prickly pear cactus by local authorities.

\section{Materials and methods}

\subsection{Insecticides treatments assays}

The insecticides used for both laboratory experiment and field study were the following: (1) sulfoxaflor (SFX, trade name Closer $^{\mathrm{TM}} 240 \mathrm{SC}$ ) at a rate of $0.179 \mathrm{~kg}$ a.i/ha, (2) diflubenzuron (DFB, trade name Dimilin ${ }^{\circledR} 25 \mathrm{~W}$ ) at a rate of $0.320 \mathrm{~kg}$ a.i/ha, and (3) mineral oil (MO, trade name Spray oil 7E) at a rate of $1.010 \mathrm{~kg}$ a.i/ha.

\subsubsection{Laboratory experiment}

2.1.1.1 Preparation of prickly pear cactus cladode samples Healthy young non-infested cladodes of prickly pear cactus of the same age planted in plastic pots were placed into a closed controlled space and exposed to cladodes heavily infested with $D$. opuntiae. After 21 days of exposure, successful natural infestation has occurred.

2.1.1.2 Insecticides application The infested cladodes previously obtained were sprayed fairly on the two sides with the appropriate insecticide solution using a knapsack sprayer of $2 \mathrm{~L}$ capacity. Five different treatments were performed on 20 cladodes. Each cladode represented a replicate, and each treatment was performed with four replications. Treatments consisted of (a) water, for control; (b) DFB; (c) DFB + MO; (d) SFX and (e) SFX+MO. The experiment was conducted during April-May 2018 and repeated twice under the same laboratory conditions $\left(T=23 \pm 4{ }^{\circ} \mathrm{C}, \mathrm{RH}=58-63 \%\right)$.

\subsubsection{Field study}

2.1.2.1 Description of the study site location and specifications The experimental cactus orchard of 12 years old used in the trial was bordering a wide hill planted with olive trees and located in Ebba, Governorate of Nabatieh-Southern Lebanon, at an altitude of $260 \mathrm{~m}$ above sea level, where, during prickly pear cactus growing season (late April-Early August), seasonal temperature varied between 20 and $35^{\circ} \mathrm{C}$, and average relative humidity ranged from 55 to $75 \%$. The orchard severely infested with $D$. opuntiae has not undergone any phytosanitary treatment before the study. No rainfall was reported during the experiment period.

2.1.2.2 Insecticides application Before insecticides application, severely infested plants were removed of the study site by pruning and later burned in order to reduce the movement of the pest. Only moderately infected prickly pear cactus were used in the trial. Insecticides application was done during spring 2018, according to the Good Agricultural Practices (GAP) using a knapsack sprayer of $16 \mathrm{~L}$ capacity under normal field conditions. The experimental field consisted of 50 plants was divided into five blocks of ten plants each. Blocks 1, 2, 3, and 4 were sprayed with $\mathrm{DFB}, \mathrm{DFB}+\mathrm{MO}, \mathrm{SFX}$, and SFX $+\mathrm{MO}$, respectively. Block 5 was sprayed with water (control). Two sprays were performed at 2 weeks interval starting at the beginning of crop growing season (late May) until the very early fruit ripening (Mid June). All plants were sprayed in the same way by the appropriate insecticide solution as to provide the correct dose of the active substance, as it is labelled on the commercial product. Three cladodes labelled $a, b$, and $\mathrm{c}$ were randomly selected on each plant of the ten plants of each block (30 cladodes per treatment) to assess D. opuntiae mortality.

\subsubsection{D. opuntiae mortality counting}

D. opuntiae population was recorded as an indicator to the efficacy of the insecticides. Number of colonies and individuals within colonies (female adults, larvae, and prepupa males if present) were initially counted before insecticides spraying for each cladode replicate in the experiments performed in the laboratory as in the field conditions. Dead individuals within colonies were next counted after $12,24,36$, and $48 \mathrm{~h}$ of spraying for the laboratory experiment, and after every 24,48 , and $96 \mathrm{~h}$ from each spray for the field study. Numbers obtained were correlated with the damage levels and expressed as $D$. opuntiae mortality mean percentages. Individuals were considered dead if a change in their colour towards light brown was detected, and a detachment of the cladodes was observed, leaving 
behind yellow to brown spots [8]. The reduction in the number of colonies and the potential newly established colonies was recorded on each cladode replicate in the field trial after 3 weeks from the second spray. Results were expressed as mean percentage of the number of present colonies.

\subsubsection{Data analysis}

Statistical analysis was performed using Statistical Package for the Social Science (SPSS19.0). Analysis procedure of variance was employed. Results were expressed as the mean \pm standard error $(\mathrm{m} \pm \mathrm{SE})$ and calculated using Descriptive. Multiple comparisons of means were made using one-way ANOVA. Post hoc tests were used to separate the means and check the homogeneity of variances. $P$ values were statistically considered significant at $5 \%$ $(P<0.05)$ level of significance.

\subsection{Insecticides residues monitoring}

At the end of the second spray of insecticides solutions (Mid June 2018), $500 \mathrm{~g}$ of fruits and $500 \mathrm{~g}$ of cladodes were randomly harvested from cactus plants from each block, after $1,3,6,9,12,15,18,21,24,27$, and 30 days of treatments. Samples taken in three replicates including watertreated control were brought immediately to the laboratory in polythene bags along with control and processed on the same day. For each sampling date, insecticides residues of the samples collected from each of the blocks were extracted with the validated QuEChERS method and diluted to $1 / 10$, and concentration was analysed by LC-MS. Thus, dissipation of insecticides residues throughout time was monitored. Day 1 is considered time $t_{0}$ where the content of insecticides residues represented $100 \%$ in comparison with the subsequently calculated values. Residues half-life times $\left(t_{1 / 2}\right)$ were further calculated by determining linear regression equation between $\operatorname{In}$ (Insecticides residues in $\mu \mathrm{g} \mathrm{kg}^{-1}$ ) and days after treatments. The days after treatments were taken on $x$-axis, and $\ln$ (Insecticides residues in $\mathrm{mg} \mathrm{kg}^{-1}$ ) was taken on $y$-axis. The method of least squares was used to find out the slope (a) of $x$ - and $y$-axis. The plots equations were calculated from the firstorder rate equation: $\ln \left[C_{t}\right]=-k t+\ln \left[C_{0}\right]$, where $C_{t}$ represents the concentration of the insecticides residues at time $t, C_{0}$ represents the initial concentration, and $k$ is the rate constant in days ${ }^{-1}$. The half-life time $\left(t_{1 / 2}=\frac{\ln 2}{k}\right)$ was determined from the $k$ value for each insecticide treatment.

\subsubsection{Insecticides residues extraction protocol}

The normalized approach QuEChERS (AOAC International Official Method ${ }^{\mathrm{SM}}$ 2007.01) for pesticides residues extraction and sample preparation [22] was performed on the collected samples of cactus fruits and cladodes. It combined the extraction/isolation process of the insecticides residues from the commodity matrices. Samples were finely homogenized, and $10 \mathrm{~g}$ sample of each was accurately weighed and transferred to a polypropylene centrifuge tube with screw cap. Ten microlitres of acetonitrile, $4 \mathrm{~g}$ of $\mathrm{MgSO}_{4}$, and $1 \mathrm{~g}$ of $\mathrm{NaCl}$ were added to the tube and the mixture shaken vigorously for $2 \mathrm{~min}$ and then centrifuged at $4{ }^{\circ} \mathrm{C}$ for $15 \mathrm{~min}$ at $2500 \mathrm{rpm}$. An aliquot of $6 \mathrm{~mL}$ of the acetonitrile phase was transferred into a dispersive solid-phase extraction (d-SPE) tube containing $900 \mathrm{mg}$ $\mathrm{MgSO}_{4}$ for the removal of water from the organic phase; $150 \mathrm{mg}$ primary secondary amine (PSA) for the removal of various polar organic acids, polar pigments, some sugars, and fatty acids; and $50 \mathrm{mg}$ graphitised carbon black (GCB) for the removal of sterols and pigments. Then, the tube was closed and shaken vigorously for $1 \mathrm{~min}$ and centrifuged for $3 \mathrm{~min}$ at $2500 \mathrm{rpm}$. The extract obtained was isolated immediately, put in a new polypropylene centrifuge tube and left in a refrigerator overnight, then filtered through a $0.2 \mu \mathrm{m}$ nylon membrane (Whatman), and transferred into a glass vial to be analysed by LC-MS.

\subsubsection{Instrumentation and LC-MS analysis conditions}

Chromatographic quantification of insecticides residues was performed on a Thermo Scientific ${ }^{\text {TM }}$ High Resolution Accurate Mass (HRAM) Liquid Chromatography coupled to a Mass Spectrometry Instrument (LC-MS).

2.2.2.1 LC analysis The chromatographic system consisted of an auto-sampler, a LC-20AD binary solvent manager, a degasser, and an automatic thermostatic column compartment. The column, equipped with a guard column, was a Thermo Scientific ${ }^{\text {TM }}$ Hypersil GOLD packed with an octadecylsilane $C_{18}$ reverse phase $(100 \mathrm{~mm} \times 2.1 \mathrm{~mm}$, $1.9 \mu \mathrm{m}$ particle size). The mobile phase consisting of $0.1 \%$ $(\mathrm{v} / \mathrm{v})$ formic acid and $10 \mathrm{mM}$ ammonium formate in water (solvent $\mathrm{A}$ ) and $0.1 \%(\mathrm{v} / \mathrm{v})$ formic acid and $10 \mathrm{mM}$ ammonium formate in methanol (solvent $B$ ) was degassed, filtered, and then pumped at a flow rate of $300 \mu \mathrm{L} \mathrm{min}$. The gradient elution program started with $98 \%(A)$ and $2 \%(B)$ reaching $70 \%(A)$ and $30 \%(B)$ at $0.25 \mathrm{~min}, 100 \%(B)$ at $10-12.5 \mathrm{~min}$ and then followed by return to the initial conditions at 13-18 $\mathrm{min}$. The column oven temperature was maintained at $40^{\circ} \mathrm{C}$, and the temperature in the sample manager was set at $5^{\circ} \mathrm{C}$. The sample volume injected was $5 \mu \mathrm{L}$. 
2.2.2.2 MS conditions A Thermo Scientific ${ }^{\text {TM }} \mathrm{Q}$ Exactive Hybrid Quadrupole-Orbitrap Mass Spectrometer (MS) was used. MS detection was performed in positive ionization mode, and the monitoring conditions were optimized for DFB and SFX residues detection. The collision energy (CE), the declustering potential (DP), the entrance potential (EP), and the collision cell exit potential (CXP) were optimized for each target analyte-insecticide analysed. Nitrogen above $99.9 \%$ purity was used as a nebulizer gas to help the evaporation of the solvent; the gas pressure was $520 \mathrm{kPa}(75 \mathrm{psi})$. The capillary ion spray voltage and the cone voltage were set at $5.0 \mathrm{kV}$ and $23 \mathrm{~V}$, respectively. The source and desolvation temperatures were held at $120^{\circ} \mathrm{C}$ and $350^{\circ} \mathrm{C}$, respectively. The cone and desolvation gas flows were 50 and $600 \mathrm{~L} \mathrm{~h}^{-1}$, respectively. Data acquisition was performed in multiple reaction monitoring (MRM) scan mode for target screening and quantification. The MS data were simultaneously acquired for selected precursor ion. The collision-induced decomposition and MS experiments were performed using helium as the collision gas, with a collision energy of $25-40 \mathrm{eV}$. Insecticides were characterized based on their mass spectra, using the precursor ion, fragment ions, and comparison of the fragmentation patterns with analytical standards. Quantification was established based on spectra of the analytical standard solutions showing the precursor ion and the calibration curves constructed.

2.2.2.3 Standard solutions preparation Individual standards solutions of DFB and SFX were used for the quantification of insecticides residues. Stock solutions at $1000 \mathrm{ppm}$ in acetonitrile were first prepared. Working standard solutions were next prepared from the stock solutions by serial dilution to build standard curves with concentration levels of 5 ppb, 10 ppb, 20 ppb, 30 ppb, 50 ppb, 70 ppb, and $100 \mathrm{ppb}$. In the same way, matrix-matched standard solutions were prepared by adding DFB and SFX standards to blank samples of fruits and cladodes of prickly pear cactus previously prepared. Linear regression of all analytical curves obtained and studied in seven concentrations ranging from 5 to $100 \mu \mathrm{g} / \mathrm{L}$ presented values of the correlation coefficient $\left(R^{2}\right)$ greater than 0.998 . All solutions were protected against light with aluminium foil and stored at $-20^{\circ} \mathrm{C}$ until use.

\subsubsection{Recovery tests}

Recovery studies were carried out to investigate the method accuracy and precision. Three replicates of spiked samples were prepared on three different days. One hundred grams of individual untreated blank samples of chopped fruits and cladodes was spiked separately with $10 \mathrm{ppb}, 20 \mathrm{ppb}, 50 \mathrm{ppb}$, and $100 \mathrm{ppb}$ of the insecticides working standard solutions and kept for $24 \mathrm{~h}$ to distribute insecticides evenly and give them time to interact with the matrices. Afterwards, spiked samples were homogenized and extracted as a normal sample as described above for the insecticides residues extraction protocol and residues analysed by LC-MS to obtain recovery rates.

\subsection{Chemicals and reagents}

All reagents and solvents were of analytical grade quality. Acetonitrile, formic acid, ammonium formate, and methanol were purchased from Fluka-Aldrich. Purified water was prepared by using the Milli-Q (Millipore, USA) water purification system. QuEChERS materials ( $\mathrm{NaCl}$, anhydrous $\mathrm{MgSO}_{4}, \mathrm{PSA}$, and GCB) were purchased from Agilent Technologies. Insecticides standards (purity ranging between 96 and $99.5 \%$ ) were purchased from Sigma-Aldrich/Chem service. Diflubenzuron and sulfoxaflor are registered in the Ministry of Agriculture of Lebanon and approved according to EC regulations Reg. (EC) No 1107/2009 (repealing Directive 91/414/EEC) [23, 24].

\section{Results and discussion}

\subsection{Rearing of $D$. opuntiae}

Rearing of $D$. opuntiae under laboratory conditions was successful due to the high rate of the insect's reproduction. Young healthy prickly pear cactus cladodes were infested almost after 3 weeks ( 21 days) of exposure to heavily infested cladodes. Colonization of the healthy cladodes depended on the first-instar larvae females that were present on the infested cladodes. These are known as "crawlers" as they possess functional legs, thus being the main responsible of spreading infestations $[25,26]$. Female nymphs of purple-red colouration that have developed long waxy dorsal filaments were observed crawling away from old colonies to set up new colonies on the healthy cladodes by walking towards the upper border of a cladode [27]. Under the cottony wax newly formed, female adults later produced approximately 200 nymphs. This was consistent with the literature, since, on average, one female lays about 131 eggs (the range is 62-617) [28]. First white-winged males were observed at 30 days after reproduction began. However, first mobile larvae were observed at 50 days, and massive outbreak of larvae took place 10 days later. Thus, at $25^{\circ} \mathrm{C}$ and $60 \%$ relative humidity, the new generation of $D$. opuntiae larvae occurred at 50 days approximately. Female nymphs entering second instar and referred as settler became motionless. After they started to feed, these nymphs tended not to move due to difficulty of inserting the long stylet into the host 
plant [9]. Progressively, chlorotic yellowish spots and necrosis appeared and prickly pear cactus cladodes began to wither to later show signs of decay. Consequently, they became depressed and began to degenerate. Approximately, 4 months later, for the second generation, total collapse and death of the cladodes were observed. All observations noted while rearing the pest under laboratory conditions such as feeding behaviour, reproduction mode, and life cycle and metamorphosis were coalesced with the literature $[3,5]$.

\subsection{Insecticides efficacy}

\subsubsection{Laboratory assay}

Figure 1 represents the efficacy of the insecticides treatments under laboratory conditions, where temperatures were recorded optimal for $D$. opuntiae development, and thus not considered as an influencing factor to the outcome of the experiment (average temperature of $23^{\circ} \mathrm{C}$ with day/night fluctuation of $\pm 4{ }^{\circ} \mathrm{C}$, relative humidity 58-63\%).

At first, 3 to 4 days after insecticides spraying, all adult male insects were observed dead for all the treatments, including control. Indeed, males are short lived [25]. On the other hand, while the mean percentage of dead individuals on cladodes treated with water (control) was relatively low and did not exceed $3 \%$ after $48 \mathrm{~h}$ of treatment, cladodes treated with DFB and SFX showed promising results. $D$. opuntiae mortality mean percentages recorded were significantly different among all the performed treatments (Fig. 1). For DFB, D. opuntiae mortality mean percentage reached $49 \%$ after $48 \mathrm{~h}$ of treatment. Treatments with SFX were observed to be more efficacious; $D$. opuntiae mortality mean started at $10 \%$ after $12 \mathrm{~h}$ of treatment and increased to $81 \%$ after $48 \mathrm{~h}$. Furthermore, results showed that adding MO to DFB and SFX improved their respective efficacy, thus enhancing $D$. opuntiae mortality mean to reach values of $95 \%$ and $98 \%$, respectively (Fig. 1). In this case, the $\mathrm{MO}$ added seemed to act as a synergist with the insecticides.

Among all treatments, best mortality records and fastest activity were recorded on SFX + MO treatment. However, it is to be noted that El Aalaoui et al. [7] showed that treatments of infested cactus plants with only mineral oil $(780 \mathrm{~g} / \mathrm{L})$ at $2400 \mathrm{cc} / \mathrm{hL}$ induce $98-100 \%$ D. opuntiae mortality $24 \mathrm{~h}$ after treatment especially among firstand second-instar nymphs, and 50\% mortality among adult females. Mineral oil interferes with the respiratory system of the insect causing it to die from asphyxiation, dissolves the external cottony waxy layer enfolding its body and protecting it from dehydration, disrupts its diet and discourages it from laying eggs (repellent effect) [9], causes death of newly hatched individuals, and creates an oily layer on eggs which stops the gases exchange and interrupts hatching. Besides, the deposit of a thin layer of MO on the crop's surface prevents settlement of newly hatched individuals $[29,30]$.

Difference observed between the efficacy of the two insecticides used as shown in Fig. 1 was presumably related to their different modes of action. For DFB, the contact insecticide's active substance acts by interference with the synthesis of chitin where it inhibits its deposition in the insect's cuticle [31]. Demand for chitin synthesis is greatest at the moult between growth stages; hence, insects are killed due to the disruption of their moulting process [31]. In this experiment, the fatal effect was seemingly occurring by the inability of the treated $D$. opuntiae individuals
Fig. 1 Efficacy of the insecticides treatments under laboratory conditions. D. opuntiae mortality mean $(\% \pm \mathrm{SE})$ after $12,24,36$, and $48 \mathrm{~h}$ of insecticides treatments. Results were obtained of two independent experiments, and each performed with four replicates. Values differ significantly among all treatments in each experiment at $P \leq 0.05$ (post hoc test, one-way ANOVA)

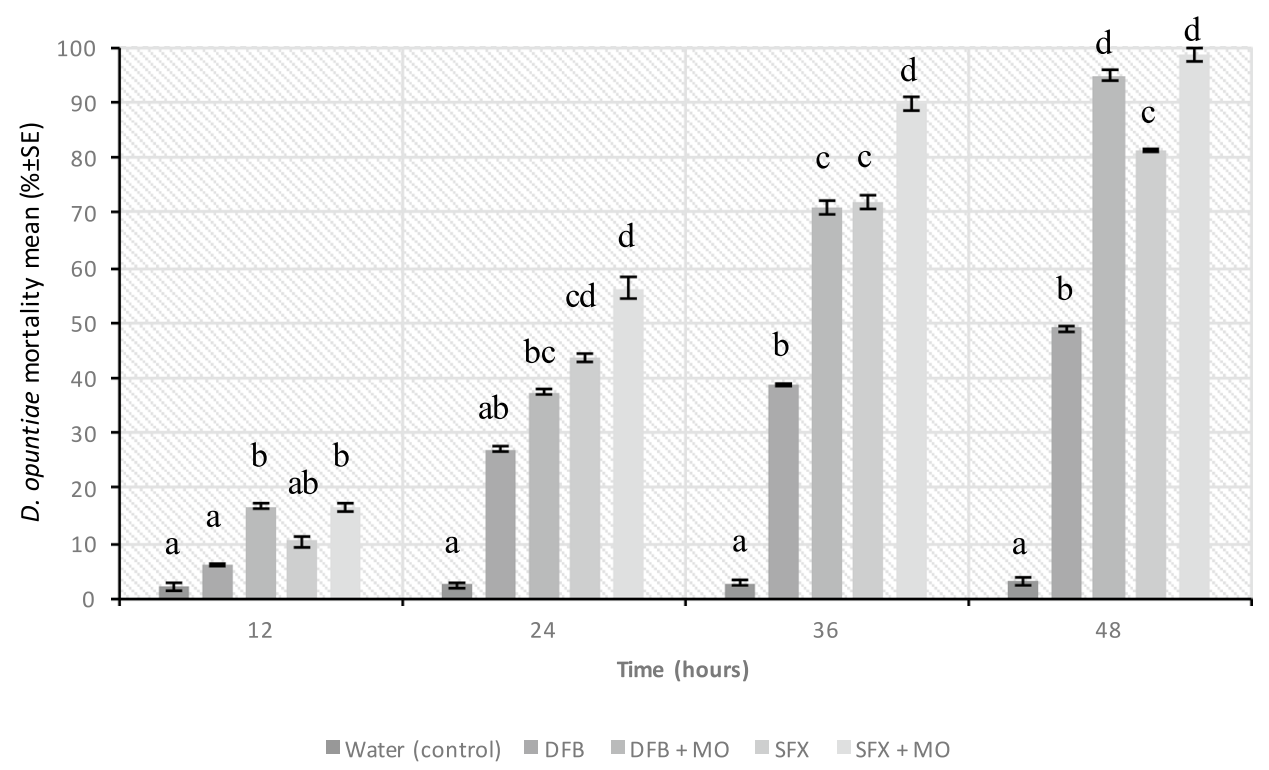


to moult properly due to incomplete development of chitin with subsequent collapse of the exoskeleton. This was mostly noticeable among first- and second-instar female larvae as they needed most production of chitin to continue development. Regarding SFX, the systemic properties of the insecticide usually ensure high potency against sap-feeding insects [32-34]. The insecticidal activity mainly originates from an agonist effect at the nicotinic acetylcholine receptor (nAChR) important in the mediation of last excitatory synaptic transmission in the insect's central nervous system [35]. In the present case, SFX was palpably active on female adults and nymphs entering the second instar as these are the only ones with ability to suck sap from cladodes and fruits, thus causing the severest damage by their feeding behaviour [27]. Male adults never feed [27]. However, action of SFX has probably occurred here by a translaminar activity since prickly pear cactus is a CAM (Crassulacean Acid Metabolism) plant with thick succulent vegetative organs that closes their stomata during the day in order to increase water use efficiency for adaptation purposes to drought stress in arid environments [36]. The insecticide seemed to have penetrated the cladodes tissues and formed a reservoir of the active ingredient within the pad which has provided residual activity against $D$. opuntiae.

As a result, for both insecticides, first- and second-instar larvae as well as female adults are the most susceptible and the easiest target for efficacious management plans [3]. However, to date, no comparative studies were available to discuss efficacy and mode of action of the insecticides used on $D$. opuntiae.

\subsubsection{Field trial}

At field conditions, the same treatments were conducted as shown in Fig. 2. The efficacy of the selected insecticides was likewise evaluated through mortality counting.

Twenty-four hours after the first insecticides spray, $D$. opuntiae mortality mean percentage was less than $40 \%$ for all the insecticidal solutions applied (Fig. 2a). Yet, values differed significantly among all treatments. In the counting at 48 and $96 \mathrm{~h}$ after spray, mortality mean percentage recorded a slight increase especially for SFX + MO treatment for which values attained $41 \%, 46 \%$, and $52 \%$ at 24 , 48, and 96 h, respectively (Fig. 2a). Cactus plants treated with DFB $+\mathrm{MO}$ also showed a decrease in the number of insects; mortality mean percentage reached values of $41 \%$, $44 \%$, and $48 \%$, respectively, at 24,48 , and 96 h of treatment. Treatments with SFX and DFB showed relatively lower mortality mean percentages $96 \mathrm{~h}$ after treatment; values were of $46 \%$ and $35 \%$, respectively (Fig. 2a). After the second spray, results also showed statistically significant difference between treatments. SFX + MO treatment had the greatest impact on $D$. opuntiae mortality that was highly and progressively recorded at 24,48 , and $96 \mathrm{~h}$ count, followed by DFB + MO treatment (Fig. 2b). At $96 \mathrm{~h}$ after treatments, mortality mean percentage reached $72 \%$, $80 \%, 88 \%$, and $92 \%$ for DFB, SFX, DFB $+\mathrm{MO}$, and SFX $+\mathrm{MO}$, respectively (Fig. 2b). The number of dead individuals was seemingly reduced more when each of the insecticides was mixed with MO that had clearly improved adherence and retention of the active ingredients on the crop surface.

At the end of the experiment, all treatments showed a remarkable reduction in the number of insects as compared to control. D. opuntiae population has significantly decreased to less than $8 \%$ when cactus plants were treated with SFX + MO. A decrease to $12 \%, 20 \%$, and $28 \%$ were, respectively, observed for the treatments with $\mathrm{DFB}+\mathrm{MO}$, SFX, and DFB. Additionally, a significant decrease in the number of colonies was recorded 3 weeks after the second spray. Less than $7 \%$ colony presence was observed for the SFX + MO treatment, followed, respectively, by $9 \%, 10 \%$, and $12 \%$ for DFB + MO, SFX, and DFB treatments (Fig. 3). Control samples, however, showed an increase in the mean number of colonies up to $136 \%$, where with each consequent date of observation, new colonies were reported to form.

As a conclusion, results obtained in field conditions were of similar trends with those previously obtained on cladodes treated in laboratory conditions. The number of insects was reducing for the two sprays performed in all the counting time series made for all the applied treatments. SFX had the highest activity and was more efficacious than DFB that has taken longer time to be active. Moreover, for all of the counts, activity of the insecticides when mixed with MO was more pronounced than when the insecticides were applied alone without the synergist. Overall findings of this trial resulted in substantial insecticidal control of $D$. opuntiae under field conditions with no evidence of phytotoxic effect. This could be promising enough in giving a relief to the farmers' community at the study area and beyond to tackle further spread and manage eventually.

On the other side, regarding side effects of the insecticides on non-target organisms, SFX could be toxic to some beneficial insects such as honeybees but only when exposed to direct spray (oral DL50 of $0.146 \mu \mathrm{g} / \mathrm{bee}$ ) or wet spray deposit. On contrary, it does not interfere with the activity of the bees once the spray deposit has dried. Concerning DFB, exposure of honeybees is negligible following the proposed use. However, DFB could prevent young larvae of natural enemy $C$. montrouzieri from being able to moult and develop into adults thus causing their death. Unfortunately, the insect population in the field plots studied was very sparse even nonexistent to be able to evaluate mortality rates after the performed sprays. 
Fig. 2 Efficacy of the insecticides treatments under field conditions. D. opuntiae mortality mean $(\% \pm \mathrm{SE})$ recorded after 24,48 , and $96 \mathrm{~h}$ of insecticides treatments for each of the two sprays performed (a Spray 1 ; b Spray 2). Five different treatments (water, for control; DFB; DFB + MO; SFX; and $\mathrm{SFX}+\mathrm{MO}$ ) were performed. For each treatment, results were obtained from 30 cladodes of ten plants. Percentages recorded after each spray are expressed according to the initial number of individuals recorded before the first spray and considered the $100 \%$ value. Values differ significantly among all treatments at $P \leq 0.05$ (post hoc test, one-way ANOVA)

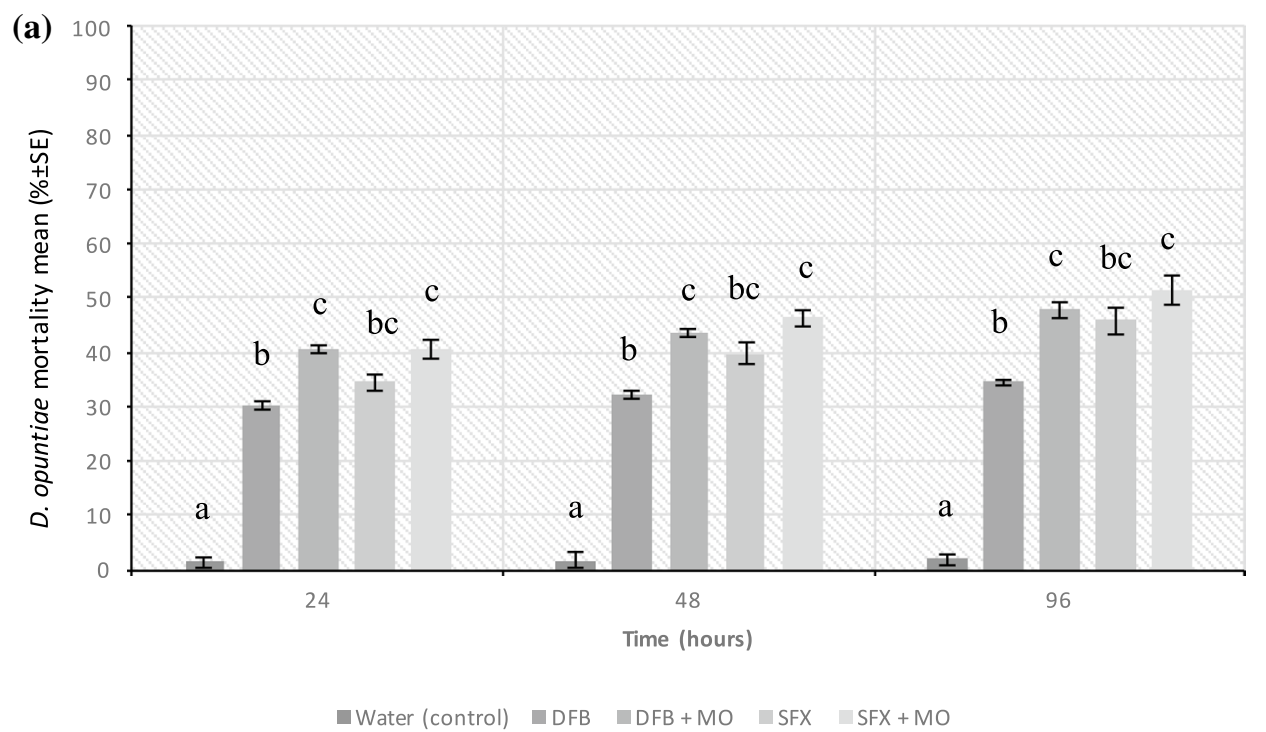

(b)

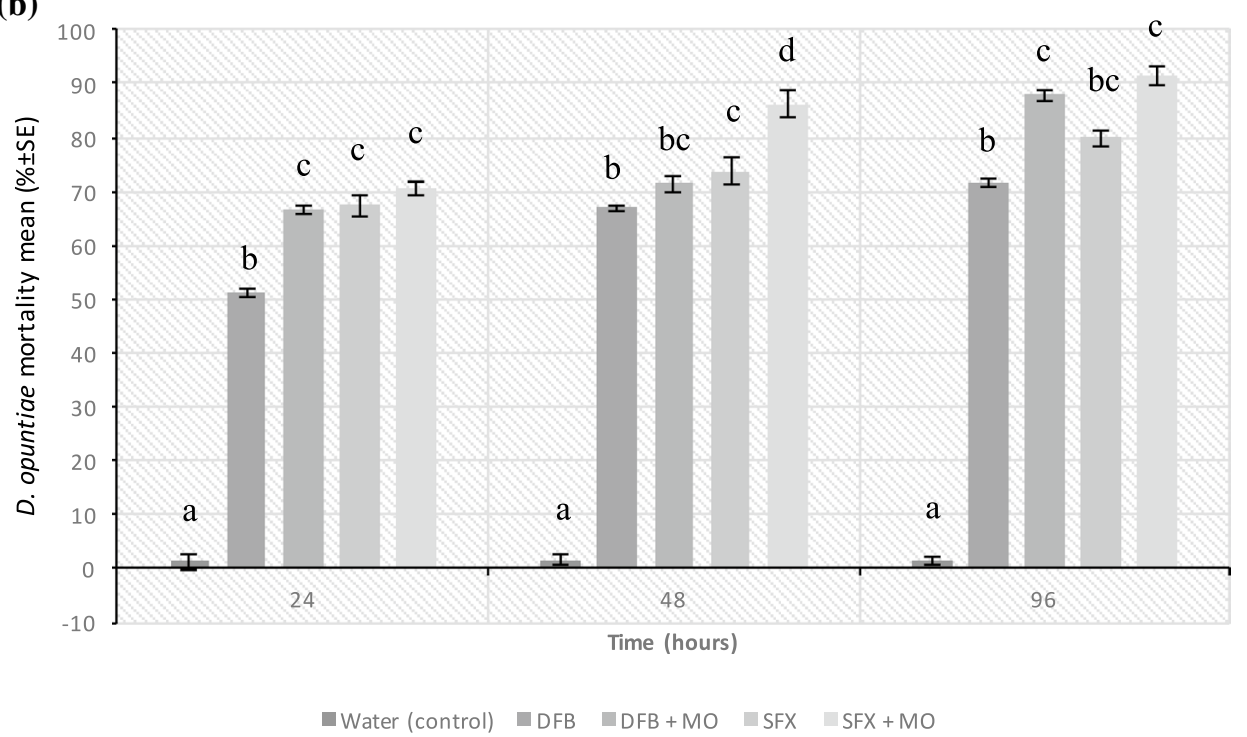

\subsection{Identification and quantification of the insecticides residues}

To overcome potential interferences of matrix effect that could affect detection of the target insecticides, matrixmatched standards of individual solutions of DFB and SFX were used for both fruits and cladodes insecticides residues analysis. Calibration curves were constructed using blank extracts of fruits and cladodes. The least squares method applied for analysis in the studied concentrations range $(5-100 \mu \mathrm{g} / \mathrm{L})$ showed linear regression that provided accurate correlation for both insecticides. The correlation coefficients were in all cases higher than 0.998 . On the other side, and under the analysis conditions, no interference peaks were observed on LC-MS chromatograms.
Retention times (RT) of DFB and SFX were $10.98 \mathrm{~min}$ and $7.43 \mathrm{~min}$, respectively. An example of the analysis of prickly pear fruits by LC-MS is represented in Fig. 4. Chromatograms of individual matrix-matched standard solutions of both insecticides, a sample spiked at $50 \mathrm{\mu g} \mathrm{kg}^{-1}$, an untreated control sample, and residues on the first day after insecticides application are represented. Peaks corresponding to the analysed insecticides are shown.

MS data collected under a multi-reaction monitoring scan mode (MRM) in positive ionization conditions using a Hybrid Quadrupole-Orbitrap Mass Spectrometer for detection are featured in Table 1. For DFB, the precursor ion $\left[\mathrm{M}+\mathrm{H}^{+}\right]$was observed at $\mathrm{m} / \mathrm{z} 311$. Two major intense fragment ions at $m / z 158$ and 313 were also observed in the molecule ion spectra and used for DBZ analysis. For 
Fig. 3 Efficacy of the insecticides treatments under field conditions. Mean of the number of colonies $(\% \pm \mathrm{SE})$ recorded after the second insecticides spray. For each treatment, results were obtained from 30 cladodes of ten plants. The initial number of colonies recorded before the first spray was considered the $100 \%$ value used to calculate the subsequent values obtained after 3 weeks of treatment. Values differ significantly among all treatments at $P \leq 0.05$ (post hoc test, one-way ANOVA)

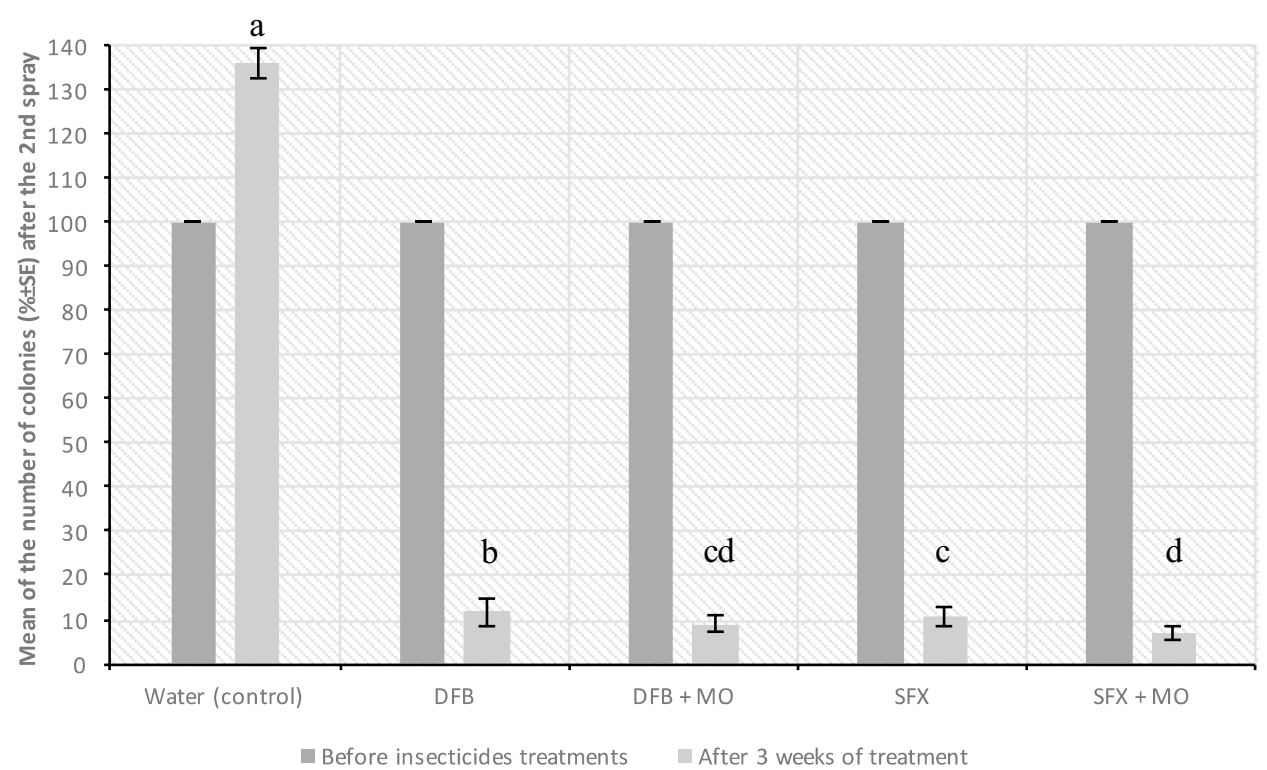

SFX, $m / z 278$ was the precursor ion and its major intense fragment ions used for identification and quantitative analysis were $m / z$ 174, 154, and 105.

\subsection{Performance of the insecticides residues determination method}

The criteria of the Codex Committee on Methods of Analysis and Sampling [37] were followed to determine the performance of the residues extraction method and the followed analysis of the residues by LC-MS. Precision and accuracy expressed in terms of recoveries of insecticides residues from prickly pear cactus samples were studied by analysing spiked samples at four different levels of concentration in triplicate measurements at three different days. Table 2 represents results obtained with fruits and cladodes matrices. For the fruits, the average recoveries calculated using matrix-matched calibration curves, ranged from 82.4 to $98.7 \%$ and from 86.3 to $94.3 \%$ for DFB and SFX, respectively, at the spiking levels studied. For the cladodes, recovery means were between 92.3 and $101.9 \%$ for DFB and between 97.5 and $99.9 \%$ for SFX. All results were in accordance with the requirements of SANCO/12495/2011 (70\% $<R<120 \%)$ [38]. Repeatability measured by comparing relative standard deviation (RSD) of recovery mean percentages of spiked samples ran on the same day, ranged from 3.1 to $11.6 \%$ for DFB and from 2.9 to $12.6 \%$ for SFX in the fruits. The cladodes revealed repeatability values that ranged between 2.7 and $10.1 \%$ for DFB and between 2.9 and $12.6 \%$ for SFX. Reproducibility, expressed as the relative standard deviation (RSD) and determined by analysing spiked samples for three different days, ranged from 3.5 to $19.6 \%$ for DFB and from 5.9 to $13.2 \%$ for SFX in the fruits, and from 7.6 to $9.2 \%$ for DFB and from 4.7 to $9.6 \%$ for SFX in the cladodes. All values were $<20 \%$ and in accordance with recommendations. Correspondingly, the method adopted for the extraction of DFB and SFX residues implied good precision and appeared to be satisfactory. LC-MS qualitative and quantitative analysis revealing consistency of the results was accordingly valid for the study of dissipation patterns of the insecticides residues.

\subsection{Dissipation rates of the insecticides residues}

The plot of the concentration of the insecticides residues in $\mu \mathrm{g} \mathrm{kg}^{-1}$ against time was used to determine the dissipation patterns of DFB and SFX in prickly pear cactus fruits and cladodes. The equations of best fit curves were determined from the maximum squares of correlation coefficients found. For the two insecticides studied in the experimental field conditions, exponential relationships were found to apply, corresponding to a first-order rate equation (Fig. 5). The linearity of the plots of In(Insecticides residues in $\mu \mathrm{g} \mathrm{kg}^{-1}$ ) against time in days was further used to graphically confirm the first-order kinetics. $R^{2}$ values ranged between 0.96 and 0.98 for DFB and between 0.93 and 0.96 for SFX (Table 3).

For DFB, the initial concentrations of the insecticide in prickly pear fruits after $24 \mathrm{~h}$ of treatment were $767.93 \mu \mathrm{g} \mathrm{kg}^{-1}$ when sprayed alone and $383.11 \mu \mathrm{g} \mathrm{kg}^{-1}$ when sprayed mixed to MO (Fig. 5a). At day 3 after treatment, these concentrations started a steady decrease. Residues content was reduced to $19.41 \%$ and $27.31 \%$ of the initial concentrations after 30 days of spray, respectively, for the treatments with DFB and DFB + MO. High 
(I)

(a)

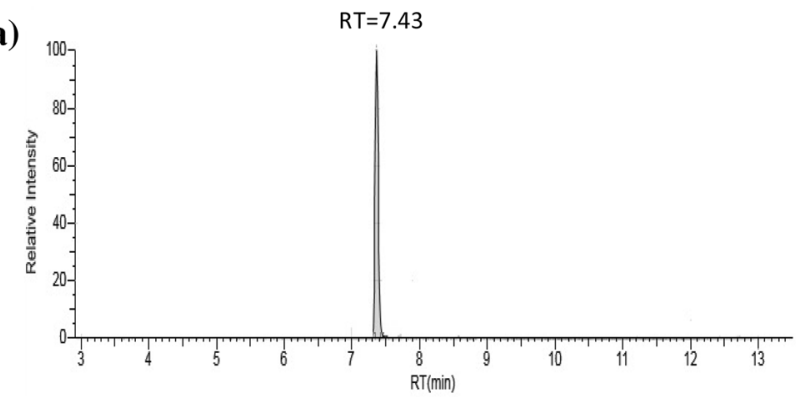

(b)

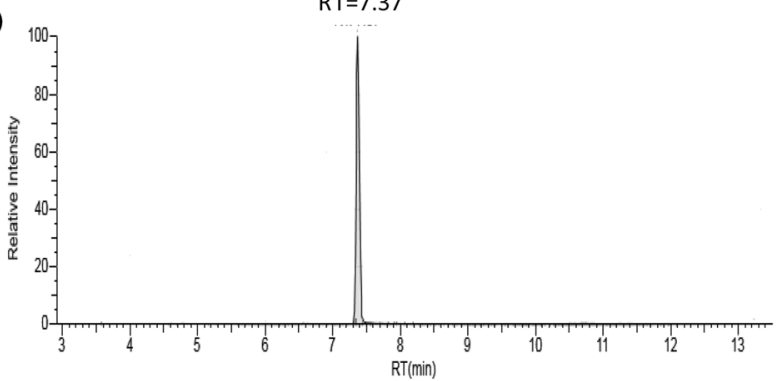

(c)

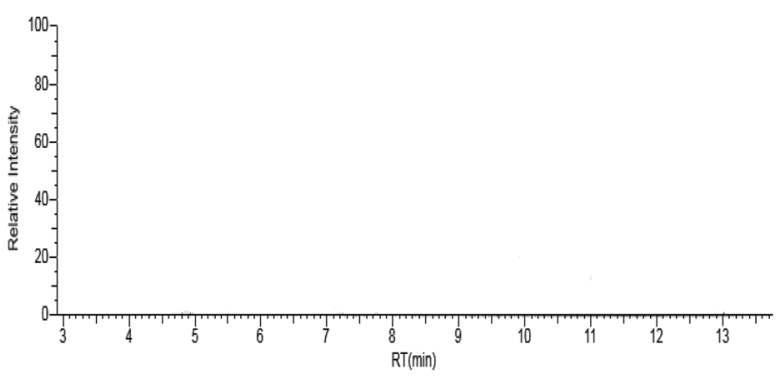

(d)

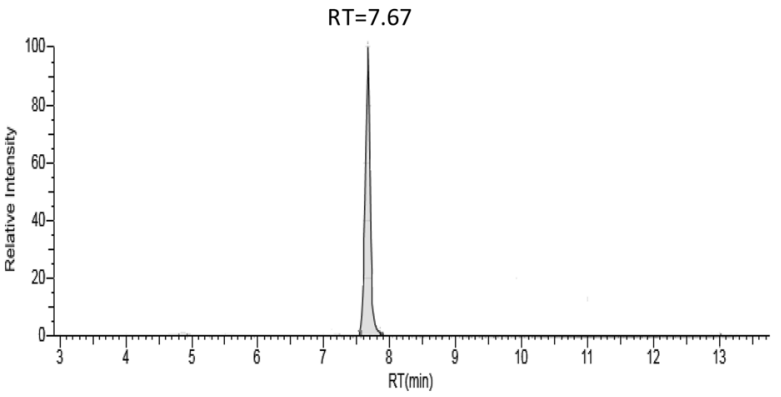

(II)

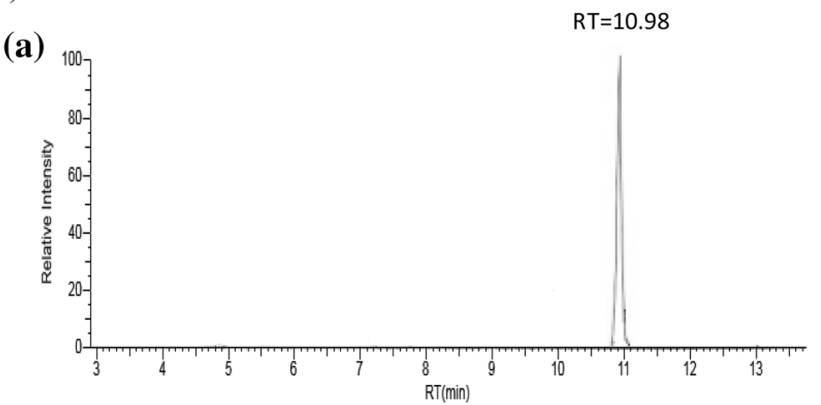

(b)

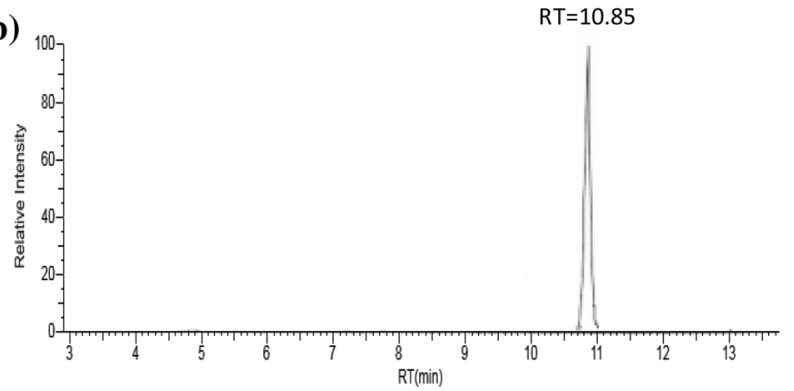

(c)

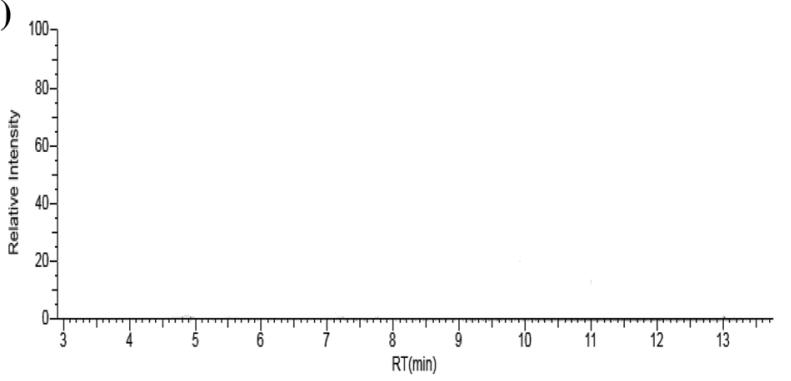

(d)

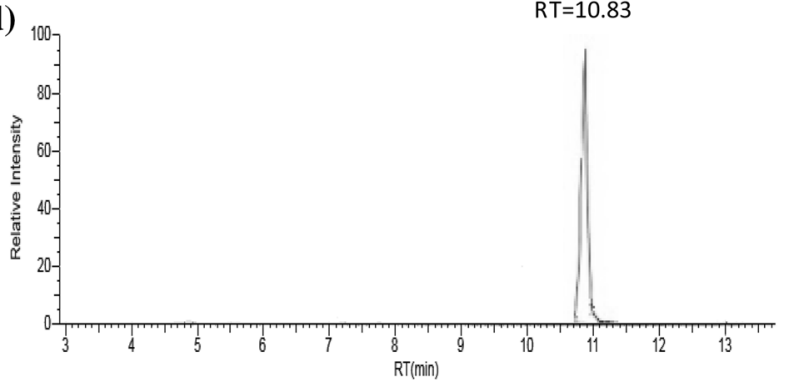

Fig. 4 Chromatogram of I SFX and II DFB a matrix-matched standard solutions, $\mathbf{b}$ a fruit sample spiked at $50 \mu \mathrm{g} \mathrm{kg}{ }^{-1}, \mathbf{c}$ the blank (control) sample, $\mathbf{d}$ residues in fruits on the first day after insecticides application

Table 1 Molecular formula and molecular weight of DFB and SFX and quantification data collected by MS in positive ionization mode under MRM scan mode

\begin{tabular}{lllll}
\hline Molecular formula & $\begin{array}{l}\text { Molecular weight } \\
\left(\mathrm{g} \mathrm{mol}^{-1}\right)\end{array}$ & $\begin{array}{l}\text { Mass fragment }(\mathrm{m} / \mathrm{z}) \text { of the } \\
\text { precursor ion }\left[\mathrm{M}+\mathrm{H}^{+}\right]\end{array}$ & $\begin{array}{l}\text { Major intense } \\
\text { fragment ions } \\
(\mathrm{m} / \mathrm{z})\end{array}$ \\
\hline $\mathrm{DFB}$ & $\mathrm{C}_{14} \mathrm{H}_{9} \mathrm{ClF}_{2} \mathrm{~N}_{2} \mathrm{O}_{2}$ & 310.68 & 311 & 158,313 \\
$\mathrm{SFX}$ & $\mathrm{C}_{10} \mathrm{H}_{10} \mathrm{~F}_{3} \mathrm{~N}_{3} \mathrm{OS}$ & 277.27 & 278 & $174,154,105$ \\
\hline
\end{tabular}



of DFB and SFX from spiked samples of prickly pear cactus fruits and cladodes and their respective relative standard deviations (RSD)
Table 2 Average recovery

\begin{tabular}{|c|c|c|c|c|c|c|c|}
\hline & \multirow{2}{*}{$\begin{array}{l}\text { Level of spik- } \\
\text { ing }\left(\mu \mathrm{g} \mathrm{kg}{ }^{-1}\right)\end{array}$} & \multicolumn{3}{|l|}{ DFB } & \multicolumn{3}{|l|}{ SFX } \\
\hline & & $\begin{array}{l}\text { Recovery } \\
\text { mean (\%) }\end{array}$ & $\begin{array}{l}\text { Repeat- } \\
\text { ability } \\
\text { (RSD\%) }\end{array}$ & $\begin{array}{l}\text { Repro- } \\
\text { ducibility } \\
\text { (RSD\%) }\end{array}$ & $\begin{array}{l}\text { Recovery } \\
\text { mean (\%) }\end{array}$ & $\begin{array}{l}\text { Repeat- } \\
\text { ability } \\
\text { (RSD\%) }\end{array}$ & $\begin{array}{l}\text { Repro- } \\
\text { ducibility } \\
\text { (RSD\%) }\end{array}$ \\
\hline Fruits & 10 & 82.4 & 13.4 & 19.6 & 86.3 & 11.2 & 13.2 \\
\hline Cladodes & & 92.3 & 10.1 & 7.6 & 97.5 & 9.6 & 5.4 \\
\hline Fruits & 20 & 86.0 & 11.6 & 12.2 & 89.9 & 12.6 & 5.9 \\
\hline Cladodes & & 97.2 & 2.7 & 7.8 & 99.9 & 11.2 & 9.6 \\
\hline Fruits & 50 & 91.2 & 7.9 & 3.5 & 91.5 & 6.6 & 7.8 \\
\hline Cladodes & & 101.9 & 4.3 & 9.2 & 98.5 & 2.9 & 4.7 \\
\hline Fruits & 100 & 98.7 & 3.1 & 5.1 & 94.3 & 3.9 & 9.8 \\
\hline Cladodes & & 97.9 & 6.3 & 8.1 & 98.9 & 8.2 & 7.9 \\
\hline
\end{tabular}

(a)

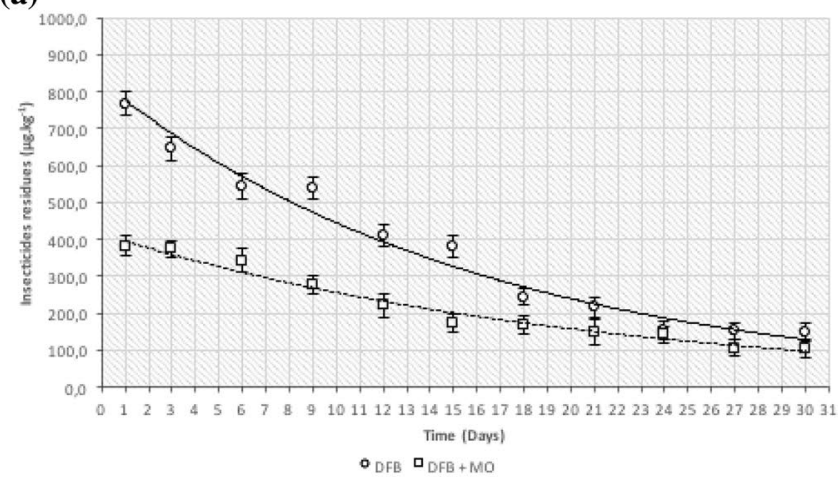

(c)

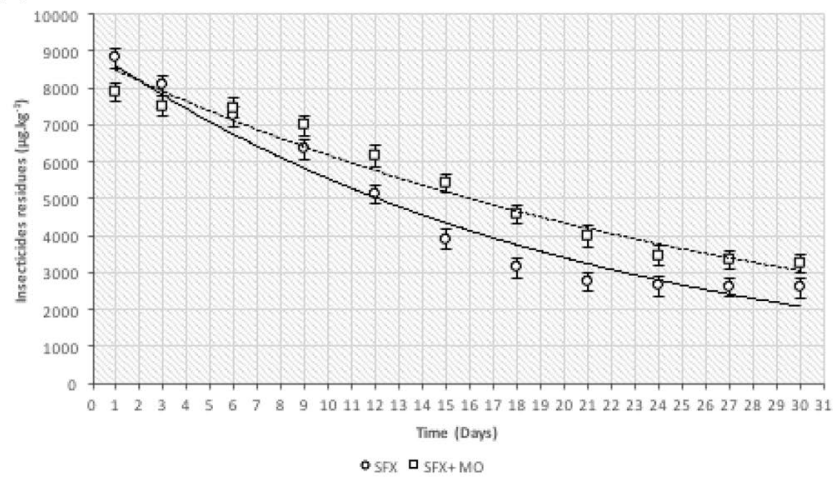

Fig. 5 Dissipation patterns of the insecticides residues in prickly pear cactus under field conditions. DFB residues in $\mathbf{a}$ fruits and $\mathbf{b}$ cladodes, and SFX residues in $\mathbf{c}$ fruits and $\mathbf{d}$ cladodes. Values are

rates of dissipation were fairly reached. Values calculated were $80.59 \%$ and $72.69 \%$, respectively (Table 3 ). The curves shape was pretty similar for the two treatments, yet dissipation of the insecticide residues was more pronounced and $1.11 \%$ higher for the treatment with DFB alone than for the treatment when $\mathrm{MO}$ was added to the active ingredient. Meanwhile, in cladodes, following application of the insecticide, the initial deposits after 1 day of application were 2694.95 and $1685.69 \mu^{~ ~ k g^{-1}}$ for the treatments with (b)

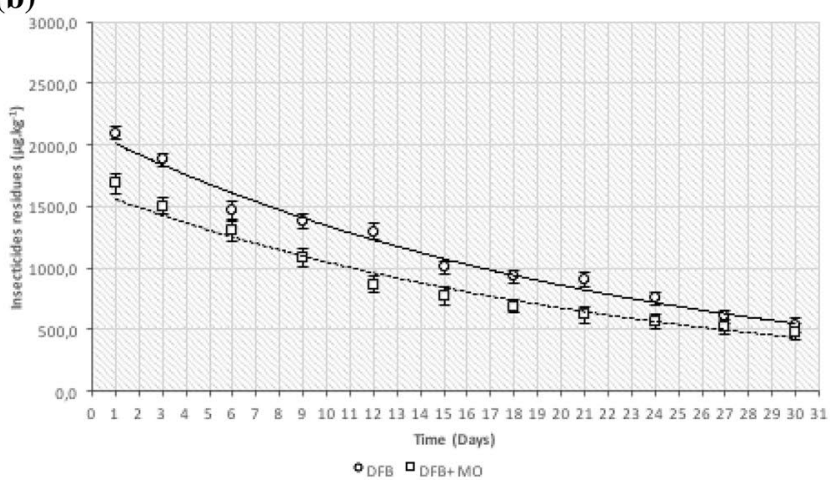

(d)

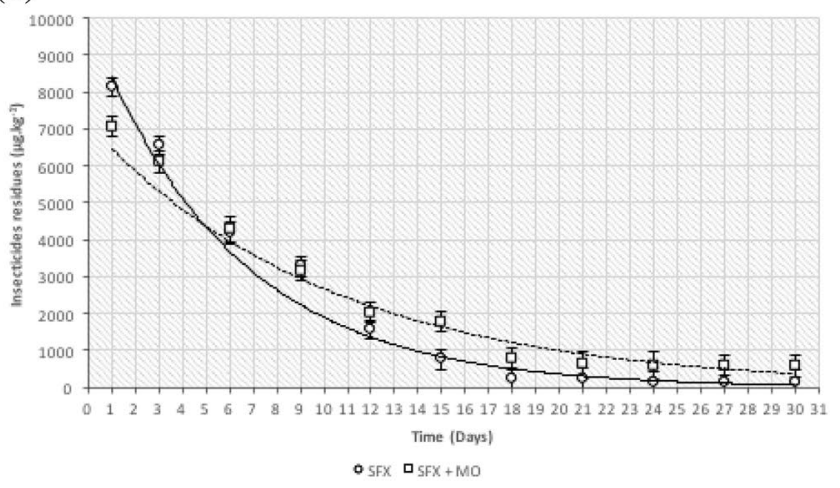

represented as mean concentration $\left(\mu \mathrm{g} \mathrm{kg} \mathrm{kg}^{-1} \pm \mathrm{SE}\right.$ ) obtained from triplicates harvested randomly from the ten plants treated in each block

DFB and DFB + MO, respectively (Fig. 5b). Afterwards, DFB residues dissipated sharply with time to reach, respectively, $25.40 \%$ and $28.55 \%$ of their initial concentrations at 30 days after treatment. High rates of dissipation were also calculated: $74.60 \%$ for the former treatment and $71.45 \%$ for the latter (Table 3). The dissipation rate was higher by $1.04 \%$ in the case of the treatment with DFB alone. Half-life times $\left(t_{1 / 2}\right)$ of DFB residues calculated from the experimental data are summarized in Table 3. Their values ranged 
Table 3 Dissipation rates and half-life times of DFB and SFX in prickly pear cactus fruits and cladodes according to performed treatment

\begin{tabular}{llllll}
\hline & Treatment & $\begin{array}{l}\text { Dissipation } \\
\text { rate }(\%)\end{array}$ & Regression equation & $\begin{array}{l}\text { Correlation coef- } \\
\text { ficient }\left(R^{2}\right)\end{array}$ & $\begin{array}{l}\text { Half-life time } \\
\left(t_{1 / 2}\right)^{\text {a }} \text { in days }\end{array}$ \\
\hline Fruits & DFB & 80.59 & $y=6.7169-0.062 x$ & 0.96828 & 11.18 \\
& DFB +MO & 72.69 & $y=6.0274-0.0484 x$ & 0.97652 & 14.32 \\
& SFX & 70.79 & $y=9.1089-0.0488 x$ & 0.94237 & 14.20 \\
& SFX + MO & 58.92 & $y=9.0812-0.0352 x$ & 0.96864 & 19.70 \\
& DFB & 74.60 & $y=7.6504-0.0448 x$ & 0.98334 & 15.47 \\
& DFB +MO & 71.45 & $y=7.3961-0.0441 x$ & 0.97381 & 15.71 \\
& SFX & 98.53 & $y=9.2055-0.1656 x$ & 0.95337 & 4.18 \\
& SFX + MO & 91.70 & $y=8.874-0.0983 x$ & 0.93221 & 7.05 \\
\hline
\end{tabular}

${ }^{a}$ Insecticides residues half-life times $\left(t_{1 / 2}\right)$ were calculated by determining linear regression equation between $\ln \left(\right.$ Insecticides residues in $\mu \mathrm{g} \mathrm{kg}^{-1}$ ) and days after treatments. The method of least squares was used to find out the apparent rate constant $(K) \cdot t_{1 / 2}=\frac{\ln 2}{K}$ from 11.18 to 15.71 days following last insecticides application and differed among fruits and cladodes. Values also differed among treatments and were higher by $1.30 \%$ for the fruits and by $1.02 \%$ for the cladodes, when DFB was mixed with $\mathrm{MO}$.

From the forgoing, at 30 days after insecticides spraying, for both fruits and cladodes, calculated dissipation rates were lower when DFB was mixed to MO (Table 3 ). These findings were probably related to the lipophilic character of the active molecule expressed by the octanol/ water partition coefficient $\log \left(K_{\text {ow }}\right)$ that is 3.89 (at $22{ }^{\circ} \mathrm{C}$, $\mathrm{pH} 3$ ) [31]. In effect, DFB if exposed to summer sunlight for a month approximately is known to lost $38-40 \%$ of the initial active molecule by volatilization taking into account that it is classified as liposoluble according to its $\log \left(K_{\text {ow }}\right)$ [31]. Therefore, the added MO probably protected DFB residues against volatilization and/or photodegradation. Consequently, the insecticides residues became more stable and, thus, dissipated less while inducing higher efficacy and mortality on D. opuntiae in this case (Fig. 2). The higher dissipation rates of the residues when DFB was applied alone were related to the characteristic stability of the molecule lost by part by volatilization and resulting thus in lower D. opuntiae mortality counting this time (Fig. 2).

On the other hand, dissipation rates were slightly higher for fruits than for cladodes (Table 3). In fact, DFB is mainly degraded by photodegradation and hydrolysis [39]. Several factors such as $\mathrm{pH}$ and temperature affect its efficacy and persistency. In diluted media, the molecule is not stable and stability is least when both $\mathrm{pH}$ and temperature are relatively high [31]. Thus, it seemed that the relatively high $\mathrm{pH}$ that the relatively high $\mathrm{pH}(5.3-7.1)$ of prickly pear fruits classified as low acid foods ( $\mathrm{pH} \geq 3.5)$ [40]; the summer temperature at the time of the experiment $\left(20-35^{\circ} \mathrm{C}\right)$ and; the high water content of prickly pear cactus [41] permitted further decrease in the stability of the insecticide and promoted its degradation especially, when used alone without the MO in the case of fruits. At the time of the experiment, no comparable studies were available on degradation patterns of DFB in prickly pear cactus. However, half-life time of 3 days at $\mathrm{pH} 10$ in highly diluted media was reported in several studies against a half-life time of 1.5 to 2 weeks at pH between 8 and 8.5 [39]. This was consistent with the values of calculated half-lives of DFB in prickly pear cactus that ranged between 11.18 and 15.71 days according to the performed treatments (Table 3 ).

For initial DFB residues concentrations at day one after application, concentrations were higher when the insecticide was used alone in comparison with when used mixed to $\mathrm{MO}$ (Fig. 5). In fact, during the insecticide spraying, the droplets volume obviously contained different amounts of the active substance in the two cases since the treatment with DFB alone consisted only of the active substance, and the treatment with DFB + MO contained the insecticide's active ingredient in association with the added MO. On the other hand, for the two treatments, the concentrations of the insecticide residues in cladodes were at all times higher than those in fruits (Fig. 5a, b). In fact, DFB is a contact insecticide; thus, great adsorption of the active molecule has probably occurred on the larger surface of the succulent ovoid-elongated shape of the cladodes. The smaller berry-like oval-shaped fruits resulted in a less insecticide adsorption during spraying.

Concerning SFX, the insecticide residues concentration also declined with time (Fig. 5). Decrease was sharper and more pronounced in cladode samples within the first 18 days and became slower after the day 21 . On contrary, a continuous decrease for fruits was observed throughout the 30 days after treatment (Fig. 5c, d). The initial concentration of SFX in cactus fruits was $8824.77 \mu \mathrm{g} \mathrm{kg}^{-1}$ when treatment with SFX alone was performed and $7884.57 \mathrm{\mu g} \mathrm{kg}^{-1}$ for the treatment with SFX + MO (Fig. 5c). Residues content reached $29.21 \%$ and $41.08 \%$ of the initial concentrations, respectively, after 30 days of application. Rates of dissipation were $70.79 \%$ for SFX and $58.92 \%$ for SFX + MO (Table 3). In the cladodes case, after $24 \mathrm{~h}$ of 
treatment, $8132.43 \mu \mathrm{g} \mathrm{kg}^{-1}$ was quantified for the treatment with SFX and $7065.15 \mathrm{\mu g} \mathrm{kg}^{-1}$ for the treatment with SFX + MO (Fig. $5 \mathrm{~d}$ ). SFX has dissipated to $1.47 \%$ and $8.30 \%$ residues content, respectively, by the 30 th day after application. Dissipation rates were $98.53 \%$ and $91.70 \%$ for SFX and SFX + MO, respectively (Table 3). Dissipation rates were higher by $1.20 \%$ and $1.07 \%$, respectively, for fruits and cladodes in the case of the treatment with SFX in comparison with the treatment with SFX + MO. Consequently, it seemed that the lower dissipation rates of SFX residues when applied simultaneously with MO have probably led to its high efficacy against $D$. opuntiae (Fig. 2). On the other hand, for SFX treatment, dissipation rate was higher by $1.39 \%$ for cladodes than for fruits, while for SFX + MO treatment, dissipation rate was higher by $1.55 \%$ for cladodes than for fruits (Fig. 5 c, d). Calculated half-lives for the systemic insecticide ranged between 4.18 and 19.70 days and differed seemingly among fruits and cladodes as well as among treatments (Table 3). In general, it was observed that half-life time value was the highest in fruits (19.70 days) treated with SFX + MO; value which was significantly higher than that in cladodes (7.05 days) treated in the same way. The lowest half-life time value was observed in cladodes ( 4.18 days) treated with SFX, while the same treatment gave a relatively higher value in fruits (14.20 days) (Table 3). Thus, half-life times were lower for both fruits and cladodes when SFX was applied alone and always lower for cladodes in comparison with fruits. Findings correlated well with the dissipation patterns of the insecticide (Fig. 5c, d). As a result, it seemed that at the same application rates and after 30 days of treatment, SFX persisted more in prickly pear cactus fruits. However, it has dissipated further and faster in cladodes (Table 3). Indeed, the literature specifically mentioned effects of plant shape and crop morphology on pesticides retention and residues degradation patterns $[42,43]$. Cladodes and fruits are physiologically and morphologically different. Cladodes hold high water mass in their thick tissue as compared to fruits $[41,44]$. Hence, they expectedly offered more dilution effect to the insecticide molecules permitting thus their relatively rapid hydrolysis and resulting in lower final residues concentrations (Fig. 5d). This was coherent with the value of the octanol/water partition coefficient of SFX $\left(\log \left(K_{\text {ow }}\right)\right)$ which is $0.802\left(\right.$ at $\left.20^{\circ} \mathrm{C}\right)$, reflecting its hydrophilic character, and this played a critical role in the understanding of the degradation kinetics of the molecule. No studies were available in the literature for confirmation or comparison of the results. However, some studies mentioned that biological half-life time of SFX in cucumber $(96 \%$ water content) is in the range of 1.6-2.9 days [43, 45]; this was slightly comparable to the pretty close consistency of cladodes (91\% water content) [46] that gave a half-life time of 4.18 days for SFX in our case. For fruits, containing a lower water amount (85\%), a half-life time of 14.20 days was obtained, indicating lower degradation activity of the insecticide residues (Table 3).

On the other side, the residues concentrations of SFX at the first day of the study were almost homogeneous and of the same order (between 7.1 and $8.8 \mathrm{mg} \mathrm{kg}^{-1}$ ) for all treatments for both fruits and cladodes (Fig. 5c, d). This was probably due to the systemic properties of SFX that has been seemingly acting with a translaminar activity in this case of the prickly pear cactus since it is a CAM plant. Moreover, initial residues concentrations were higher for the treatment with SFX alone in comparison with those for the treatment with SFX + MO. In fact, in the latter case, the insecticide solution is a mixture of the two ingredients which subsequently decreased the amount of SFX molecules in the droplets volume.

SFX and DFB were assessed in the framework of the EU pesticides peer review under regulation Reg. (EC) No $1107 / 2009$ and reviewed by the European Commission under Directive 91/414/EEC [23, 24]. For SFX, data were sufficient to derive an acceptable daily intake (ADI) of $0.04 \mathrm{mg} / \mathrm{kg}$ bw/day and an acute reference dose (ARfD) of $0.25 \mathrm{mg} / \mathrm{kg}$ bw/day (Reg. (EU) 2015/1295) [24]. For DFB, an ADI of $0.1 \mathrm{mg} / \mathrm{kg}$ bw/day was set; ARfD is not applicable (Reg. (EU) 2017/885) [23]. Basing on the insecticides ADI values, the contact insecticide seemed to be the residue of interest for dietary risk assessment and the safest for use. Yet, these insecticides are not registered for utilization on Opuntia species; therefore, no maximum residues levels (MRLs) in cactus fruits and cladodes were set to date. Consequently, the common and default MRL of $0.01 \mathrm{mg} \mathrm{kg}^{-1}$ established by the EU at the lower limit of analytical determination should be used for results discussion and data assessment ("A general default MRL of $0.01 \mathrm{mg} / \mathrm{kg}$ applies where a pesticide is not specifically mentioned", EU legislation on MRLs) [47]. For all the treatments performed and for both insecticides, residual levels in fruits as well as in cladodes were above the default MRL throughout the days of the study. Concentrations in $\mathrm{mg} \mathrm{kg}^{-1}$ of the insecticides residues at 30 days after application of the treatments were the following: DFB (fruits: 0.149; cladodes: 0.531 ), DFB + MO (fruits: 0.105 ; cladodes: 0.481 ), SFX (fruits: 2.578; cladodes: 0.120 ), and SFX + MO (fruits: 3.239; cladodes: 0.586 ). As a result, it seemed that the crop has to be harvested far after 30 days to reach the limits of detection mentioned by the EU in this case. SFX was the most persistent, and its residues concentrations in fruits were the higher, exceeding by large the default MRL. Besides, even though SFX residues half-life time for cladodes was lower than DFB residues half-life time, final concentrations of the systemic insecticide remained largely above the MRL value. 
Naturally, dissipation patterns of this study could be useful to determine specific MRLs for the insecticides in prickly pear cactus. Nevertheless, in order to complete the present findings and minimize the insecticides residues content, further studies are needed to determine the major metabolites resulting from the respective degradation behaviour of the insecticides under field conditions. On the other hand, more studies on the mode of action of the insecticides are also needed in order to define the best moment of intervention. Meantime, differences on $D$. opuntiae survival according to weather conditions in the infested areas studied were observed between the years of 2018 and 2019. In 2018, a low rainfall amount $(88.18 \mathrm{~mm}$; 78 days) was recorded on fall, winter, and spring seasons (November 2017-April 2018) and relatively higher temperatures $\left(10-18^{\circ} \mathrm{C}\right)$ than the seasonal averages have occurred. Increase in $D$. opuntiae population was thus observed in the infested areas surveyed during summer 2018 (June 2018-September 2018). Indeed, damages are known to be predominant during low precipitation periods and could become more severe as drought advances [27]. Contrariwise, field surveys during spring and summer of 2019 (April 2019-August 2019) showed a real decline in the population due to the heavy precipitations (391.04 mm; 140 days) and low temperatures $\left(5-16^{\circ} \mathrm{C}\right)$ that have occurred this year during the whole fall, winter, and spring seasons (November 2018-April 2019). In all of the plots surveyed in southern Lebanon, $>99 \%$ mortality was observed. Indeed, some studies reported that temperatures below $20^{\circ} \mathrm{C}$ and above $30^{\circ} \mathrm{C}$ have negative effects on the productivity of $D$. opuntiae [48]. Other studies reported that the lower temperature threshold for the development of $D$. opuntiae is $14.4 \pm 0.9^{\circ} \mathrm{C}$; however, it can survive on cut cladodes for several weeks, while tolerating dry climates and high temperature reaching up to $40^{\circ} \mathrm{C}$ [49]. Heavy rain is also known to harm the population and reduces its development as it removes the protective wax of the colonies that increases its vulnerability to natural enemies, and it can also remove nymphs from the cladodes [49].

\section{Conclusion}

In recent years, southern prickly pear cactus cultivations in Lebanon were aggressively infested by $D$. opuntiae. With no official effective management to date, the purpose of this paper was to evaluate and compare the efficacy of two insecticides (sulfoxaflor and diflubenzuron) in controlling its spread. Results revealed that the two could be promising candidates. Sulfoxaflor has highly and effectively reduced $D$. opuntiae population at the two sprays performed in the time intervals indicated and was scarcely more efficacious than diflubenzuron. Separate addition of mineral oil synergist to the insecticides ameliorated their respective activity. Findings are interesting in broadening the spectrum of chemical alternatives for the pest management and reducing random pesticides applications by local farmers. Concerning dissipation rates of the insecticides residues over time, sulfoxaflor residues were more persistent in prickly pear fruits than diflubenzuron residues. On contrary, sulfoxaflor residues dissipated further in cladodes. The added mineral oil decreased dissipation rates for both and increased respective half-lives. These observations were related to morphological differences between fruits and cladodes and to the chemical molecular structure and properties of the insecticides. The extraction, identification, and quantification methods used for residues analysis showed satisfactory validation parameters in terms of linearity, accuracy, and precision. Therefore, it could be used for registration of the insecticides on prickly pear cactus and setting respective MRLs. Moreover, dissipation rates equations could be used to compute residues at any point time to ensure safe application of the insecticides and to set minimum intervals between application and harvest. However, kinetics of dissipation patterns of the metabolites which could be derived from the respective active molecules of the insecticides still need to be better elucidated and require further analysis.

Acknowledgements The authors deeply thank the Lebanese University for financially supporting this project. They also thank Mr. Malek Tarhini from Ebba municipality as well as the research team who have participated to completion of the study and in particularly Dr. Dalida Darazi, Entomologist and lecturer at the Faculty of Agricultural Engineering and Veterinary Medicine of the Lebanese University. The authors would also like to express their gratitude to the reviewers for their careful reading and insightful comments and suggestions.

Author contributions All authors contributed to the study conception and design. Material preparation, data collection and analysis were performed by $\mathrm{RZ}, \mathrm{SH}, \mathrm{LM}$, and $\mathrm{KE}-\mathrm{O}$. Funding acquisition was granted for RZ. Supervision was performed by SD. The first draft of the manuscript was written by RZ, and all authors commented on previous versions of the manuscript. All authors read and approved the final manuscript.

Funding This work was supported by grant from the Research Program of the Lebanese University (Grant No. 4/5531).

\section{Compliance with ethical standards}

Conflict of interest The authors declare that they have no conflict of interest. 


\section{References}

1. El-Mostafa K, El Kharrassi $Y$, Badreddine A, Andreoletti $P_{1}$ Vamecq J, El Kebbaj MS, Latruffe N, Lizard G, Nasser B, Cherkaoui-Malki M (2014) Nopal cactus (Opuntia ficus-indica) as a source of bioactive compounds for nutrition, health and disease. Molecules 19(9):14879-14901. https://doi.org/10.3390/ molecules190914879

2. Chalak L, Younes J, Rouphael S, Hamadeh B (2012) Morphological characterization of prickly pears (Opuntia ficus indica (L.) Mill.) cultivated in Lebanon. Int J Sci Res 3(6):2541-2553

3. Torres JB, Giorgi JA (2018) Management of the false carmine cochineal Dactylopius opuntiae (Cockerell): perspective from Pernambuco state, Brazil. Phytoparasitica 46(3):331-340. https ://doi.org/10.1007/s12600-018-0664-8

4. Moussa Z, Yammouni D, Azar D (2017) Dactylopius opuntiae (Cockerell, 1896), a new invasive pest of the cactus plants Opuntia ficus-indica in the South of Lebanon (Hemiptera, Coccoidea, Dactylopiidae). Bulletin de la Société Entomologique de France 122(2):173-178

5. Mazzeo G, Nucifora S, Russo A, Suma P (2019) Dactylopius opuntiae, a new prickly pear cactus pest in the Mediterranean: an overview. Entomol Exp Appl 167(1):59-72. https:// doi.org/10.1111/eea.12756

6. Borges LR, Santos DC, Gomes EWF, Cavalcanti VALB, Silva IMM, Falcão HM, da Silva DMP (2013) Use of biodegradable products for the control of Dactylopius opuntiae (Hemiptera: Dactylopiidae) in cactus pear. ISHS Acta Hortic 995:379-386. https://doi.org/10.17660/ActaHortic.2013.995.49

7. El Aalaoui M, Bouharroud R, Sbaghi M, El Bouhssini M, Hilali L, Dari K (2019) Comparative toxicity of different chemical and biological insecticides against the scale insect Dactylopius opuntiae and their side effects on the predator Cryptolaemus montrouzieri. Arch Phytopathol Plant Prot 52:155-169. https ://doi.org/10.1080/03235408.2019.1589909

8. Fitiwy I, Gebretsadkan A, Araya A (2016) Management of cochineal (Dactylopius coccus Costa) insect pest through botanical extraction in Tigray, North Ethiopia. J Drylands 6(2):499-505

9. Vigueras AL, Cibrían-Tovar J, Pelayo-Ortiz C (2009) Use of botanicals extracts to control wild cochineal (Dactylopius opuntiae Cockerell) on cactus pear. Acta Hortic 811:229-234. https://doi.org/10.17660/ActaHortic.2009.811.28

10. Bouharroud R, Sbaghi M, Boujghagh M, El Bouhssini M (2018) Biological control of the prickly pear cochineal Dactylopius opuntiae Cockerell (Hemiptera: Dactylopiidae). Bull OEPP/ EPPO Bull 48(2):300-306. https://doi.org/10.1111/epp.12471

11. Cruz-Rodríguez JA, González-Machorro E, Villegas González AA, Rodríguez Ramírez ML, Mejía Lara F (2016) Autonomous biological control of Dactylopius opuntiae (Hemiptera: Dactyliiopidae) in a prickly pear plantation with ecological management. Environ Entomol 45(3):642-648. https://doi. org/10.1093/ee/nvw023

12. Badii MH, Flores AE (2001) Prickly pear cacti pests and their control in Mexico. Florida Entomol 84(4):503-505

13. Pretorius MW, Van Ark H (1992) Further insecticide trials for the control of Cactoblastis cactorum (Lepidoptera: Pyralidae) as well as Dactylopius opuntiae (Hemiptera: Dactylopiidae) on spineless cactus. Phytophylactica 14(3):229-234

14. Thiamethoxam. Reg. (EC) No $1107 / 2009$ and Reg. (EU) No 2018/524. https://ec.europa.eu/food/plant/pesticides/eupesticides-database/public/?event=activesubstance.detai I\&language $=E N \&$ selectedID $=1937$. Accessed 21 Jan 2019

15. Bifenthrin. Reg. (EC) No 1107/2009. https://ec.europa.eu/food/ plant/pesticides/eu-pesticides-database/public/?event=activ esubstance.detail\&language $=E N \&$ selectedID $=1026$. Accessed 21 Jan 2019

16. Parathion-methyl. Reg. (EC) No 1107/2009. https://ec.europa.eu/ food/plant/pesticides/eu-pesticides-database/public/?event $=$ activesubstance.detail\&language $=E N \&$ selectedID $=1671$. Accessed 21 Jan 2019

17. Dimethoate. Reg. (EC) No $1107 / 2009$ and Reg. (EU) No 2019/1090. https://ec.europa.eu/food/plant/pesticides/eu-pesti cides-database/public/?event=activesubstance.detail\&langu age $=E N \&$ selectedID $=1247$. Accessed 15 June 2019

18. Carbaryl. Reg. (EC) No 1107/2009. https://ec.europa.eu/food/ plant/pesticides/eu-pesticides-database/public/?event=activ esubstance.detail\&language $=E N \&$ selectedID $=1079$. Accessed 21 Jan 2019

19. Official Gazette of Lebanon No 15/2019, pp 1040-1041. http:// www.legallaw.ul.edu.lb/LawArticles.aspx?LawArticleID=10997 79\&Lawld=280758. Accessed 27 May 2019

20. CODEX ALIMENTARIUS International Food Standards/FAO. Pesticide Database. Fl 0356-Prickly pear. http://www.fao.org/faowho-codexalimentarius/codex-texts/dbs/pestres/commoditie s-detail/en/?c_id=456. Accessed 10 Oct 2019

21. European Commission/EU Pesticides Database. Code number 0162040-Prickly pears/Cactus fruits https://ec.europa.eu/food/ plant/pesticides/eu-pesticides-database/public/?event=produ ct.displayAll\&language $=E N \&$ selectedID $=69$. Accessed $10 \mathrm{Oct}$ 2019

22. Lehotay SJ, O'Neil M, Tully J, Valverde Garca A, Contreras M, Mol $\mathrm{H}$, Heinke V, Anspach T, Lach G, Fussell R, Mastovska K, Poulsen ME, Hammack W, Cook JM, Alder L, Lindtner K, GamnVila M, Hopper M, de Kok A, Hiemstra M, Schenck F, Williams A, Parker A (2007) Determination of pesticide residues in foods by acetonitrile extraction and partitioning with magnesium sulfate: collaborative study. J AOAC Int 90(2):485-520

23. Diflubenzuron. Reg. (EC) No 1107/2009 (repealing Directive 91/414/EEC). https://ec.europa.eu/food/plant/pesticides/eupesticides-database/public/?event=activesubstance.detai I\&language $=E N \&$ selectedID $=1236$. Accessed 18 July 2018

24. Sulfoxaflor. Reg. (EC) No 1107/2009 (repealing Directive 91/414/ EEC). https://ec.europa.eu/food/plant/pesticides/eu-pesti cides-database/public/?event=activesubstance.detail\&langu age $=E N \&$ selectedID $=2282$. Accessed 18 July 2018

25. Moran VC (1980) Interactions between phytophagous insects and their Opuntia hosts. Ecol Entomol 5(2):153-164. https://doi. org/10.1111/j.1365-2311.1980.tb01136.x

26. Zimmermann HG, Granata G (2002) Insect pests and diseases. In: Nobel PS (ed) Cacti: biology and uses. University of California Press, Berkeley, pp 235-254

27. Mow VC, Gunn BH, Walter GH (1982) Wind dispersal and settling of first-instar crawlers of the cochineal insect Dactylopius austrinus (Homoptera: Coccoidea: Dactylopiidae). Ecol Entomol 7(4):409-419. https://doi.org/10.1111/j.1365-2311.1982.tb006 83. $\mathrm{x}$

28. Flores-Hernández A, Murillo-Amador B, Rueda-Puente EO, Salazar-Torres JC, García-Hernández JL, Troyo-Diéguez E (2006) Reproducción de cochinilla silvestre Dactylopius opuntiae (Homóptera: Dactylopiidae) (Reproduction of wild cochineal Dactylopius opuntiae (Homoptera: Dactylopiidae)). Revista Mexicana de Biodiversidad 77:97-102

29. Moustafa OK, El-Attal ZM (1985) Enhancement of the efficiency of some insecticides against thrips and cotton leafworm by mineral oils. J Agric Sci 105(1):63-66. https://doi.org/10.1017/S0021 859600055714

30. Pree DJ, Stevenson AR, Barszcz ES (1996) Toxicity of pyrethroid insecticides to carrot weevils: enhancement by synergists and oils. J Econ Entomol 89(5):1254-1261. https://doi.org/10.1093/ jee/89.5.1254 
31. Rath S, Friedlander L, Reuss R (2015) Diflubenzuron. In: Residue evaluation of certain veterinary drugs. FAO JECFA Monographs 18. Joint FAO/WHO Expert Committee on Food Additives, 81st meeting 2015. Rome, pp 13-44. ISSN 1817-7077. http://www. fao.org/3/a-i5590e.pdf

32. Zhu Y, Loso MR, Watson GB, Sparks TC, Rogers RB, Huang JX, Gerwick BC, Babcock JM, Kelly D, Hegde VB, Nugent BM, Renga JM, Denholm I, Gorman K, Deboer GJ, Hasler J, Meade T, Thomas JD (2011) Discovery and characterization of sulfoxaflor, a novel insecticide targeting sap-feeding pests. J Agric Food Chem 59(7):2950-2957. https://doi.org/10.1021/jf102765x

33. Babcock JM, Gerwick CB, Huang JX, Loso M, Nakamura G, Nolting SP, Rogers RB, Sparks TC, Thomas J, Watson GB, Zhu Y (2010) Biological characterization of sulfoxaflor, a novel insecticide. Pest Manag Sci 67(3):328-334. https://doi.org/10.1002/ps.2069

34. Xu J, Dong F, Liu X, Li J, Li Y, Shan W, Zheng Y (2012) Determination of sulfoxaflor residues in vegetables, fruits and soil using ultra-performance liquid chromatography/tandem mass spectrometry. Anal Methods 4:4019-4024. https://doi.org/10.1039/ C2AY25782C

35. Watson GB, Loso MR, Babcock JM, Hasler JM, Letherer TJ, Young CD, Zhu YM, Casida JE, Sparks TC (2011) Novel nicotinic action of the sulfoximine insecticide sulfoxaflor. Insect Biochem Mol Biol 41(7):432-439. https://doi.org/10.1016/j.ibmb.2011.01.009

36. Bowes B, Mauseth J (2008) Plant structure: a color guide, 2nd edn. Jones and Bartlett Publishers, Burlington

37. CX/MAS 02/4, Codex Alimentarius Commission, Codex Committee on Methods of Analysis and Sampling (FAO/WHO), Proposed draft guidelines for evaluating acceptable methods of analysis, Agenda Item 4a of the 24th Session, Budapest, Hungary, 18-22 November 2002+CX/MAS 02/4-Add.2 Dispute situations. https ://ec.europa.eu/food/safety/international_affairs/standard_setti ng_bodies/codex/ccmas/archives_en. Accessed 7 Sept 2018

38. SANCO/12495/2011. Method validation and quality control. Procedures for pesticide residues analysis is food and feed. http:// www.crl-pesticides.eu/library/docs/fv/SANCO12495-2011.pdf. Accessed 7 Sept 2018

39. Zaidi N, Farine JP, Soltani N (2013) Experimental study on diflubenzuron: degradation in freshwater and bioconcentration in mosquitofish following chronic exposure. J Environ Prot 4(2):188-194. https://doi.org/10.4236/jep.2013.42022

40. Sawaya WN, Khatchadourian HA, Safi WM, Al Hammad HM (1983) Chemical characterization of prickly pear pulp, Opuntia ficus-indica, and the manufacturing of prickly pear jam. J Food Technol 18(2):183-193. https://doi. org/10.1111/j.1365-2621.1983.tb00259.x

41. Maki-Díaz G, Peña-Valdivia CB, García-Nava R, Arévalo-Galarza L, Calderón-Zavala G, Anaya-Rosales S (2015) Physical and chemical characteristics of cactus stems (Opuntia ficus-indica) for exportation and domestic markets. Agrociencia 49(1):31-51

42. Buchholz A, Trapp S (2016) How active ingredient localisation in plant tissues determines the targeted pest spectrum of different chemistries: intracellular localisation of insecticides. Pest Manag Sci 72(5):929-939. https://doi.org/10.1002/ps.4070

43. Opolot M, Lee SH, Kwak SY, Sarker A, Cho SC, Kim HJ, Jeong HR, Kim JE (2018) Dissipation patterns of insecticide sulfoxaflor in spinach and Korean cabbage. Korean J Pestic Sci 22(4):316-326

44. Nebbache S, Chibani A, Chadli R, Bouznad A (2009) Chemical composition of Opuntia ficus-indica (L.) fruit. Afr J Biotechnol 8(8):1632-1634

45. Chen Z, Dong F, Pan X, Xu J, Liu X, Wu X, Zheng Y (2016) Influence of uptake pathways on the stereoselective dissipation of chiral neonicotinoid sulfoxaflor in greenhouse vegetables. J Agric Food Chem 64(13):2655-2660. https://doi.org/10.1021/ acs.jafc. 5 b05940

46. Sáenz C, Corrales García J, Aquino Pérez G (2002) Nopalitos, mucilage, fiber, and cochineal. In: Nobel PS (ed) Cacti: biology and uses. University of California Press, Berkeley, pp 211-234

47. New rules on pesticide residues in food. EU legislation on MRLs. https://ec.europa.eu/food/plant/pesticides/max_residue_level s/eu_rules_en. Accessed 11 June 2018

48. Karny M (1972) Comparative studies on three Dactylopius species (Homoptera: Dactylopiidae) attacking introduced opuntias in South Africa. Entomological Memoir of the Department of Agriculture and Technical Services of the Republic of South Africa, vol 26, pp 1-19

49. Moran VC, Hoffmann JH, Basson NCJ (1987) The effects of simulated rainfall on cochineal insects (Homoptera: Dactylopiidae): colony composition and survival on cactus cladodes. Ecol Entomol 12(1):51-60. https://doi.org/10.1111/j.1365-2311.1987. tb00984.x

Publisher's Note Springer Nature remains neutral with regard to jurisdictional claims in published maps and institutional affiliations. 